\title{
Epidemiological Aspects of Clostridium difficile in a Pediatric Hospital and its Role in Diarrheal Disease
}

\author{
M. Camorlinga-Ponce ${ }^{1}$, M. Gamboa ${ }^{1}$, J. J. Barragan ${ }^{1}$, O. Munoz ${ }^{1}$, F. R. Fekety ${ }^{2}$, J. F. Torres ${ }^{3 *}$
}

\begin{abstract}
The influence of antibiotics on the frequency of colonization by Clostridium difficile and the presence of its cytotoxin in infants and older children was examined to determine its role in diarrheal disease. Cytotoxin was more closely associated with cases of diarrhea, both in infants and in children than the microorganism, although not significantly. The isolates were typed by means of sensitivity to bacteriophages and bacteriocins and their cytotoxigenic potential was also determined. Less than $30 \%$ of the colonized patients had toxigenic strains. A study of strain variability over a four-year period in the same hospital showed that two bacteriophage-bacteriocin types and non-toxigenic strains predominated. The common presence of non-toxigenic strains could explain in part the lack of correlation between isolation of Clostridium difficile and diarrhea. Most of the non-toxigenic strains showed moderate resistance to tetracycline, a property which might explain their ability to persist for long periods in the hospital.
\end{abstract}

While the role of Clostridium difficile in antibioticassociated pseudomembranous colitis and diarrhea in adults is well defined $(1,2)$, its pathogenicity in children is unclear. Clostridium difficile rarely produces pseudomembranous colitis in children (3), and its role in diarrheal disease remains to be determined (4-6). A high proportion of infants may be colonized and have the toxins in their gut without any obvious symptoms $(7-9)$. The frequency of infection depends on the population studied. Only a few studies have been done in asymptomatic children older than one year, in whom the frequency of colonization is less than in younger infants but higher than observed in adults $(8,9)$. The mechanism responsible for this age-related refractoriness to the toxins and the associated factors which increase the risk for disease need to be determined.

The aim of this study was to examine the role of Clostridium difficile and its cytotoxin in diarrhea in infants (less than one year of age) and children (1 to 15 years old). Patients involved in this study were at equal risk of infection since all attended the same department. The influence of antibiotics

\footnotetext{
${ }^{1}$ Unidad de Investigacion en Enfermedades Infecciosas, Instituto Mexicano del Seguro Social, Facultad de Medicina, Edificio A 2do. piso, Ciudad Universitaria, Mexico, Distrito Federal, Mexico.

${ }^{2}$ Division of Infectious Diseases, Department of Internal Medicine, R-6022 Kresge II, University of Michigan, Ann Arbor, Michigan 48109, USA

${ }^{3}$ Department of Medical Microbiology, University of Göteborg, Guldhedsgatan 10,413 46 Göteborg, Sweden.
}

on the frequency of colonization in these children was also studied. Strain variability over a four year period was examined in infants in the same hospital. Strains isolated in this study were compared to strains isolated in a previous study (10).

\section{Materials and Methods}

Patients. A total of 123 infants and 150 children hospitalized in the infectious diseases department of the Pediatric hospital at the Medical Center, IMSS Mexico, and at similar risk of infection participated in the study. Seventy-four percent of the patients were receiving antibiotic therapy; most ( $70 \%)$ were on three or more antibiotics, whereas less than $10 \%$ took only one antibiotic. Ampicillin and gentamicin were used most frequently. Stool samples were taken on a weekly basis for one year (August 1984 - July 1985). More than one sample was collected from some children if they were in the department for one week or more. Specimens were sent to the laboratory and divided into two portions; one was processed on the same day for Clostridium difficile culture and the other was kept at $-20^{\circ} \mathrm{C}$, usually for two or three days, until it was processed for cytotoxin.

Stool Culture. Feces were mixed with phosphate buffered saline (PBS) at pH 7.4 in a proportion of $1: 1$ and then diluted ten-fold in the same buffer. A $0.1 \mathrm{ml}$ sample of both the $1: 10$ and $1: 1000$ dilutions was used to inoculate CCFA media (11) containing $250 \mu \mathrm{g} / \mathrm{ml}$ of cycloserine and $8 \mu \mathrm{g} / \mathrm{ml}$ of cefoxitin, respectively. At least two characteristic colonies per plate were identified by previously described methods (12). Strains of Clostridium difficile were grown and maintained in chopped meat media for further study.

Cytotoxin Assay. Feces were mixed with PBS (1:1), centrifuged at $6000 \mathrm{rpm}$ for $15 \mathrm{~min}$ and the supernatant was filter- 
sterilized and processed for cytotoxin in Chinese Hamster Ovary cells (CHO). Positive samples diluted $1: 10$ to $1: 10,000$ were tested with and without Clostridium difficile antitoxin obtained from the Anaerobe Lab at Virginia Polytechnical Institute and State University. Clostridium difficile isolates were grown for $48 \mathrm{~h}$ in brain heart infusion broth (Difco, USA) and the supernatant was processed as the fecal filtrates for cytotoxin. For the assay, CHO cells werc grown in F-12 media (Gibco, USA) with $5 \%$ foetal calf serum (In Vitro, Mexico) on a 96-well flat-bottomed microplate for $24 \mathrm{~h}$ and then inoculated with $20 \mu$ of each sample. Plates were incubated at $37^{\circ} \mathrm{C}$ in a $5 \% \quad \mathrm{CO}_{2}-95 \%$ air humidified atmosphere. Samples were considered positive when at least $50 \%$ of the cells became round and this activity could be neutralized with Clostridium difficile antitoxin.

Typing Scheme. Clostridium difficile isolates were identified by their sensitivity to bacteriophages and bacteriocins as described elsewhere (13). Strains from one type did not differ in more than one bacteriophage and/or no more than one bacteriocin from the indicated pattern. Eighteen strains of Clostridium difficile isolated from infants in the same hospital in a previous study (10) were also identified using this scheme.

Antibiotic Susceptibility. Strains were assayed for susceptibility to penicillin, ampicillin, cefoxitin, clindamycin, amikacin, gentamicin, kanamycin, cycloserine, chloramphenicol, tetracycline and metronidazole. Antibiotics were tested in two-fold dilutions to give final concentrations from 0.25 to $1024 \mu \mathrm{g} / \mathrm{ml}$ of the antimicrobial agent in brucella blood agar as described (12).

\section{Results}

The use of antibiotics was associated with a significantly diminished frequency of colonization in infants $(7.1 \%)$ as compared with infants not receiving antibiotics $(32 \%, p<0.05)$. The presence of cytotoxin was not affected (Table 1). In contrast, the use of antibiotics in children favored colonization by the microorganism ( $10.5 \%$ with; $4.3 \%$ without), although the difference was not significant $(p>0.05)$. The presence of the microorganism in infants or children was independent of the presence or absence of diarrhea, although cytotoxin was more common in patients with diarrhea (Table 1). This association was more marked in infants than in children, though not statistically different ( $\mathrm{p}>0.05)$.

Two Clostridium difficile isolates per patient were chosen for further study. If the isolates proved to be the same bacteriophage and bacteriocin type, they were considered one isolate. If they were different types, they were analyzed separately. Forty-three different strains were identified and studied for production of cytotoxin in vitro. Of these strains, $63 \%$ were non-toxigenic. Most of the toxigenic strains were isolated from infants, whereas non-toxigenic strains were more often isolated from children (Table 2). No correlation was found between toxigenicity of the strains and presence of cytotoxin in stool specimens. The frequency with which more than one type of strain was isolated from the same patient was calculated (Table 3). Twelve of the 31 positive patients $(39 \%)$ had more than one type of strain, but in only two of these patients were both identified types toxigenic. The other ten patients had at least one non-toxigenic type. Among the other 19 patients, only one type of strain was isolated per sample $(61 \%)$.

The susceptibility to different antimicrobial agents was not useful for typing the strains: 20 different patterns were obtained which correlated poorly with toxigenicity and bacteriophage and bacteriocin typing. However, sensitivity to tetracycline was related to a strain's toxigenic potential (Figure 1). Most toxigenic strains were sensitive to less than $2 \mu \mathrm{g} / \mathrm{ml}$ tetracycline, and all strains resistant to $64 \mu \mathrm{g} / \mathrm{ml}$ or more were non-toxigenic.

The bacteriophage and bacteriocin pattern of the strains isolated in this study were compared with 18 strains isolated in a previous study (Table 4). Two of the more commonly isolated types in this study ( $\mathrm{A}$ and $\mathrm{B}$ ) were also the more common types among previous isolates (period 1981-1982). Most strains of these types were non-toxigenic. Some types were present only among 1981-1982 isolates ( $\mathrm{C}$ and $\mathrm{H}$ ) and others were found only in strains from this study (D, E, F, I and J). Type F was also

Table 1: Isolation of Clostridium difficile and its cytotoxin from infants and children with or without antibiotic and with or without diarrhea. Number positive is given over number tested (percentage in parenthesis).

\begin{tabular}{lccccc}
\hline & \multicolumn{2}{c}{$\begin{array}{c}\text { Infants }(<1 \text { year } \\
\mathrm{n}=123\end{array}$} & & \multicolumn{2}{c}{$\begin{array}{c}\text { Children (1-15 years) } \\
\mathrm{n}=150\end{array}$} \\
\cline { 2 - 4 } Condition & $\begin{array}{c}\text { Clostridium difficile } \\
+\end{array}$ & $\begin{array}{c}\text { cytotoxin } \\
+\end{array}$ & & $\begin{array}{c}\text { Clostridium difficile } \\
+\end{array}$ & $\begin{array}{c}\text { cytotoxin } \\
+\end{array}$ \\
\hline Previous antibiotics & $7 / 98(7.1)$ & $5 / 98(5.1)$ & & $11 / 104(10.5)$ & $6 / 104(5.7)$ \\
No previous antibiotics & $8 / 25(32)$ & $1 / 25(4.0)$ & & $2 / 46(4.3)$ & $1 / 46(2.8)$ \\
Diarrhea present & $4 / 30(13)$ & $3 / 30(10)$ & & $0 / 13$ & $1 / 13(7.7)$ \\
Diarrhea absent & $11 / 93(12)$ & $3 / 93(3.2)$ & & $13 / 137(9.5)$ & $6 / 137(4.4)$ \\
\hline
\end{tabular}


Table 2: Number of strains of Clostridium difficile isolated from infants and children which produced cytotoxin (percentage in parenthesis).

\begin{tabular}{|c|c|c|c|}
\hline Origin of isolates & Total & Toxigenic $^{\mathbf{a}}$ & Non-toxigenic \\
\hline Infants $(<1$ year $)$ & 21 & $11(52)$ & $10(48)$ \\
\hline Children ( 1 to 15 years) & 22 & $5(23)$ & $17(77)$ \\
\hline
\end{tabular}

${ }^{a}$ Cytotoxic activity was measured on Chinese Hamster Ovary cells.

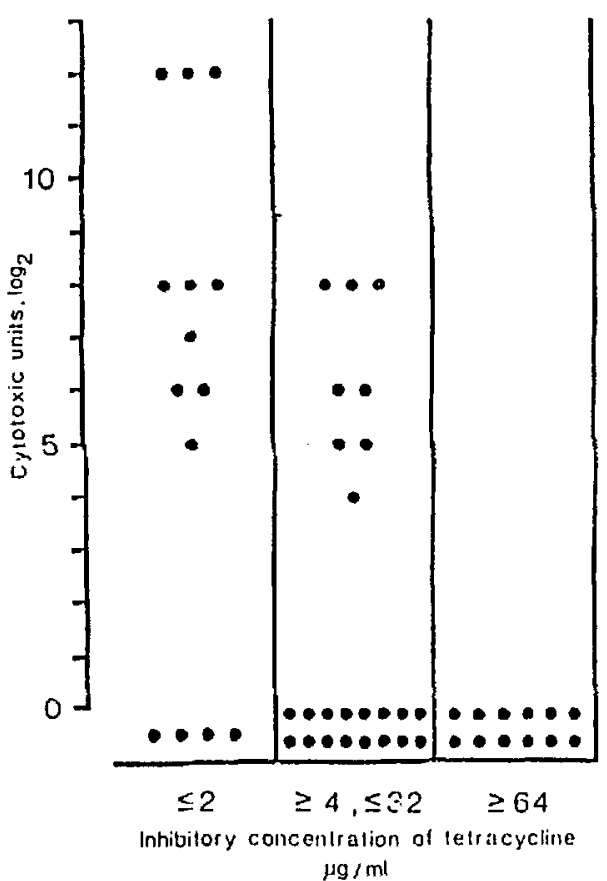

Figure 1: Relationship between sensitivity to tetracycline and production of cy totoxin by Clostridium difficile strains isolated from infants and children. common in this study, and strains with this pattern had a broad spectrum of cytotoxicity (from nontoxigenic to highly toxigenic). All three isolates of type D were found to be toxigenic. Isolates from the period 1984-1985 were also classified according to their origin; they were considered to be community. acquired if present in admission cultures and hospitalacquired if admission cultures were first negative but became positive after $72 \mathrm{~h}$ of hospitalization. Among the 43 isolates, $24(56 \%)$ were hospital-acquired, $6(14 \%)$ community-acquired, and not enough data were obtained to classify the remaining 13 isolates. All type A isolates were hospital-acquired, whereas the other types were found in both hospital-acquired and community-acquired isolates.

\section{Discussion}

We studied the influence of the patient's age and the use of antibiotics on the frequency of colonization and on the consequence, if any, of this colonization in patients receiving similar medical treatment under uniform conditions of environmental risk of infection. The influence of antibiotics on the rate of colonization by Clostridium difficile was found to be age dependent (Table 1): infants showed a significantly reduced frequency of colonization, whereas colonization was enhanced in children. This inhibitory effect of antibiotics on the colonization in infants has been reported by others $(8,14)$.

The frequency of cytotoxin in feces of infants was not reduced by antibiotics, despite the reduction of colonization. One possible reason for this discrepancy is the high proportion of non-toxigenic strains in these patients (see Table 2). In children, both cytotoxin and the microorganism were more frequently found in association with antibiotic therapy, a response similar to that seen in adults.

Table 3: Frequency of colonization of children by one or by two types of Clostridium difficile and its relation to diarrhea.

\begin{tabular}{llcrl}
\hline Classification of patients & $\begin{array}{l}\text { Toxigenicity of the } \\
\text { identified types }\end{array}$ & $\begin{array}{l}\text { Number of } \\
\text { patients }\end{array}$ & $\begin{array}{c}\text { Diarrhea } \\
\text { present }\end{array}$ & absent \\
\hline $\begin{array}{l}\text { Patients colonized with } \\
\text { two different types }\end{array}$ & $\begin{array}{l}\text { a } \\
\text { non-tox and non-tox } \\
\text { non-tox and tox } \\
\text { tox and tox }\end{array}$ & 5 & - & 4 \\
$\begin{array}{l}\text { Patients colonized with } \\
\text { one type }\end{array}$ & $\begin{array}{l}\text { non-tox } \\
\text { tox }\end{array}$ & 12 & - & 5 \\
& & 7 & 2 & 10 \\
\hline
\end{tabular}

${ }^{a}$ Strains were typed according to their sensitivity to bacteriophages and bacterjocins. 
Table 4: Identification of strains of Clostridium difficile isolated during a four-year period in a pediatric hospital according to their susceptibility to bacteriophages and bacteriocins.

\begin{tabular}{|c|c|c|c|c|c|c|}
\hline \multirow{3}{*}{ Pattern of sensitivity ${ }^{a}$} & \multirow{3}{*}{ Designated type } & \multirow{3}{*}{$\begin{array}{c}\text { Total } \\
\text { isolates }\end{array}$} & \multicolumn{4}{|c|}{$\begin{array}{l}\text { Distribution according to period } \\
\text { of isolation and } \\
\text { toxigenicity } b\end{array}$} \\
\hline & & & \multicolumn{2}{|c|}{$1981-1982$} & \multicolumn{2}{|c|}{$1984-1985$} \\
\hline & & & tox & non-tox & tox & non-tox \\
\hline \multicolumn{7}{|l|}{ Refractory to all bacteriophages and } \\
\hline bacteriocins tested & A & 17 & 1 & 4 & 1 & 10 \\
\hline Cld $7 ; \mathrm{B} 1537$ & B & 18 & 0 & 9 & 1 & 8 \\
\hline Cld $16,17,19$ & $\mathrm{C}$ & 2 & 2 & 0 & - & - \\
\hline B83, 778, 809, 1995, 33A, 806 & $\mathrm{D}$ & 3 & - & - & 3 & 0 \\
\hline $\mathrm{B} 1811,810,1481,1320,1700$ & $\mathrm{E}$ & 1 & - & - & 0 & 1 \\
\hline Cld2, $13 ; \mathrm{B} 1811,810,1481,1320,1700$ & $F$ & 11 & - & - & 6 & 5 \\
\hline \multicolumn{7}{|l|}{ Cld $2,6,9,11,13,16,17,19$} \\
\hline B1811, 810, 1481, 1320, 1700, 1537 & $\mathrm{G}$ & 6 & 1 & 0 & 1 & 4 \\
\hline $\operatorname{Cld} 16,19 ; \mathrm{B} 1811,810,1481,1320,1700$ & $\mathrm{H}$ & 1 & 1 & 0 & - & - \\
\hline Cld $14,15,16,17,19,20,21,22 ;$ B1537 & I & 2 & - & - & 2 & 0 \\
\hline Cld $11,13,14,15,16,17,19,20,21,22 ;$ B1537 & $\mathbf{J}$ & 1 & - & - & 1 & 0 \\
\hline
\end{tabular}

${ }^{a}$ Sensitivity to bacteriophages is indicated by $\mathrm{Cld}$ and to bacteriocins by $\underline{B}$; the following numbers refer to the stock number of the phages or bacteriocins active against the isolates.

bToxigenicity was measured on Chinese Hamster Ovary cells.

We also looked for any association of the microorganism with diarrheal episodes (Table 1). There was no relation between Clostridium difficile isolation and diarrhea in either infants or children. There were more cytotoxin-positive samples from patients with diarrhea than without diarrhea, but this difference was not significant. Similar results have been obtained in other studies $(4,5,8)$.

Reports that Clostridium difficile and its cytotoxin may be present in asymptomatic children have been documented. However, since many cases of diarrhea have been associated with this microorganism $(3,15)$, it should not be disregarded as a possible agent. The presence of cytotoxin might be a better diagnostic test, but we should first establish the factors favouring disease. Our results suggest that antibiotics are not one of the risk factors in infants and children.

We also studied the possibility that a patient colonized with toxigenic strains could be colonized concomitantly with non-toxigenic strains, which could in turn inhibit the toxigenic strains in vivo (16). Almost $40 \%$ of the colonized patients had more than one type of strain per patient (Table 3). A considerable proportion of patients with toxigenic strains also had non-toxigenic strains. Although the number of cases of diarrhea among these patients was too low to draw any conclusion, the results suggest that children may frequently be colonized with toxigenic and non-toxigenic strains at the same time.

The fact that more than $60 \%$ of the isolates were not able to produce cytotoxin in vitro strongly suggests that the isolation of the microorganism is not a reliable diagnostic test. Our finding that nontoxigenic strains account for almost $50 \%$ of these strains in infants has been reported by others (17). That the opposite has also been reported suggests that the population studied is more important than the age of the individuals.

In a study conducted two years ago in the same hospital, we also found a higher proportion of nontoxigenic than toxigenic strains. Most of the nontoxigenic strains isolated in this study belong to the two more common bacteriophage-bacteriocin types (A and B, Table 4), which were also most abundant among the isolates in our previous study. The toxigenic strains were less stable between 1981-1982 and 1984-1985. This long predominance of nontoxigenic strains could be explained in part by the higher sensitivity of toxigenic strains to tetracycline (see Figure 1), since resistant strains and nontoxigenic strains would have a better chance of surviving. The significance of this relationship is being studied further.

The persistence of types $A$ and $B$ over four years could be due to a continued contamination of the environment by these strains. Interestingly, all type A isolates were hospital-acquired in this study. A long chain of transmission from patient to patient or personnel to patient seems unlikely. These results provide further evidence for the importance of Clostridium difficile as a source of hospital infection, and suggest some strains may persist for years in the same environment. Strain variability among isolates 
from the same patient should be studied in more detail to assess the possible correlation between predominance of a certain toxigenic type and disease.

\section{Acknowledgements}

This work was supported in part by grant PCS ABN/021544 from Consejo Nacional de Ciencia y Tecnologia, Mexico.

\section{References}

1. Gilligan, P. H., McCarthy, L. R., Genta, V. M.: Relative frequency of Clostridium difficile in patients with diartheal disease. Journal of Clinical Microbiology 1981, $14: 26-31$.

2. Gebhard, R. L., Gerding, D. N., Olson, M. M., Peterson, L. R., McClain, C. J., Ansel, H. J., Shaw, M. J., Schwartz, M. L.: Clinical and endoscopic findings in patients early in the course of Clostridium difficile-associated pseudomembranous colitis. American Journal of Medicine 1985, 78: 45-48.

3. Viscidi, R. P., Bartlett, J. G.: Antibiotic-associated pseudomembranous colitis in children. Pediatrics 1981, 67: $381-386$.

4. Elstner, C. L., Lindsay, A. N., Book, L. S., Matsen, J. M.: Lack of relationship of Clostridium difficile to antibiotic-associated diarrhea in children. Pediatric Infectious Disease 1983, 2: 364-366.

5. Hyams, J. S., Feder, H., Krause, P. J., Frick, J., McLaughlin, J. C., Furth, T., Hine, P.: Occurrence of Clostridium difficile toxin-associated gastroenteritis following antibiotic therapy for otitis media in young children. Pediatric Infectious Disease 1984, 3: 433436.
6. Merida, V., Moerman, J., Colaert, J., Lemmens, P. Vandepitte, J.: Significance of Clostridium difficile and its cytotoxin in children. European Journal of Pediatrics 1986, 144: 494-496.

7. Donta, S. T., Myers, M. G.: Clostridium difficile toxin in asymptomatic neonates. Journal of Pediatrics 1982, 100: $431-434$.

8. Holst, E., Helin, I., Mârdh, P. A.: Recovery of Clostridium difficile from children. Scandinavian Joumal of Infectious Disease 1981, 13:41-45.

9. Stark, P. L., Lee, A., Parsonage, B. D.: Colonization of the large bowel by Clostridium difficile in healthy infants: quantitative study. Infection and Immunity $1982,35: 895-899$.

10. Torres, J. F., Cedillo, R., Sanchez, J., Dillman, C., Giono, S., Munoz, O.: Prevalence of Clostridium difficile and jts cytotoxin in infants in Mexico. Journal of Clinical Microbiology 1984, 20: 274-275.

11. George, W. L., Sutter, V. L., Citron, D., Finegold, S. M.: Selective and differential medium for isolation of Clostridium difficile. Journal of Clinical Microbiology $1979,9: 214-219$.

12. Holdeman, L. V., Cato, E. P., Moore, W. E. C.: Anaerobe laboratory manual. Virginia Polytechnic Institute and State University, Blacksburg, Virginia, 1977.

13. Sell, T. L., Schaberg, D. R., Fekety, F. R.: Bacteriophage and bacteriocin typing scheme for Clostridium difficile. Journal of Clinical Microbiology 1983, 17: $1148-1152$

14. Zedd, A. J., Sell, T. L., Schaberg, D. R., Fekety, F. R., Cooperstock, M.S.: Nosocomial Clostridium difficile reservoir in a neonatal intensive care unit. Pediatric Infectious Disease 1984, 3:429-432.

15. Kim, K., DuPont, H. L., Pickering, L. K.: Outbreak of diarrhea associated with Clostridium difficile and its toxin in day-care centers: evidence of person-to-person spread. Journal of Pediatrics 1983, 102: 376-382.

16. Wilson, K. H., Sheagren, J. N.: Antagonism of toxigenic Clostridium difficile by nontoxigenic Ciostridium difficile. Journal of Infectious Diseases 1983, 147: $733-736$.

17. Larson, H. E., Barclay, F. E., Honour, P., Hill, I. D.: Epidemiology of Clostridium difficile in infants. Journal of Infectious Diseases 1982, 146: 727-733. 